\title{
EFFECTS AND DEFECTS OF THE POLYPROPYLENE PLATE FOR DIFFERENT PARAMETERS IN FRICTION STIR WELDING PROCESS
}

\author{
K. Panneerselvam ${ }^{1}$, K. Lenin ${ }^{2}$ \\ ${ }^{1}$ Assistant Professor, ${ }^{2}$ Research Scholar, Department of Production Engineering, NITT, Tamil Nadu, India \\ kps@nitt.edu, leninnaga@yahoo.com
}

\begin{abstract}
Polypropylene is one of the thermoplastic materials used in the lot of engineering applications such as marine, aerospace, automotive, toys and etc. Friction Stir Welding (FSW) is a solid-state method of used for joining metals. FSW process was successfully extended to join thermoplastic materials. In this paper an attempt has been made to understand the mechanism of friction stir welding joints of polypropylene plates. In this study, the role of FSW tool pin profile, rotational speed and welding speed are analyzed with respective to the quality of the joints. This research outlines the method of welding and optimization of FSW process parameters for polypropylene material by Taguchi optimization methodology. Experiments were performed at rotational speed of 1500, 1750, 2000 and $2250 \mathrm{rpm}$, Welding speeds of 30,40, 50 and $60 \mathrm{~mm} / \mathrm{min}$, and tool pin profiles of Triangular, square, Threaded and taper pin profiles. The experiments are conducted in CNC vertical machining centre with special fixture. Microstructural characteristics were evaluated by using optical microscopy and hardness are observed in weld joints. The micro structure and Rockwell hardness of the welded region was created by threaded pin profile with welding speed of 40 and $50 \mathrm{~mm} / \mathrm{min}$ and rotational speed of 2250 and 1500 rpm act as right friction stir welding parameters to avoid defects in joining of polypropylene materials.
\end{abstract}

Index Terms: Polypropylene, Microstructure, Hardness, Pin profile, Speed, Feed, and Weld zone

$* * *$

\section{INTRODUCTION}

Friction stir welding (FSW) is a novel solid-state welding process for the joining of metallic alloys and composites; it is the numerous applications in manufacturing situations $[1,2]$. FSW considered to be one of the most significant welding processes, FSW has the advantage of non-consuming fabrication of continuous linear welds, the most common form of weld joint configuration. This joining technique is energy efficient, environmentally friendly and versatile [3]. In general, the process is carried out by plunging a rotating FSW tool into the interface of two rigidly clamped sheets, until the shoulder touches the surface of the material being welded, and transverse along the weld line. The frictional heat and deformation heat are utilized for the bonding under the applied normal force [4]. This process is illustrated in Fig-1. The microstructure of copper material with those of the residual friction stir welded zone was compared and characterized by using optical microscopy (OM) and transmission electron microscopy (TEM). Tensile strength and corresponding microhardness profiles through the weld zone were also correlated with these microstructures. Hardness variation also existed in the stir zone from the top to the lower region with thermal and mechanical conditions [5]. The hardness distribution in the weld nugget, thermal-mechanical affected zone, heat affected zone and the base metal were evaluated by using Vickers hardness tests on the welds. The temperature on the retreating side were slightly lower than those on the advancing side. But, there is no significant difference in hardness between the advancing and retreating sides [6].

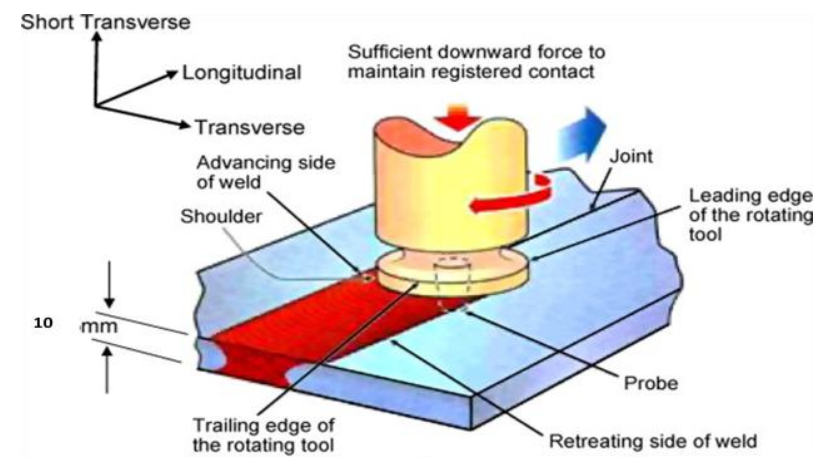

Fig-1: Friction stir welding process

The hardness of the stirred zone for 10 to $30 \mathrm{~mm} / \mathrm{sec}$ feed rate for 1000 to 2000rpm had explained in the magnesium alloys [7]. The hardness of the material had only evaluated based on composition of magnesium, silicon and silicon carbide. They had not explained thoroughly about the changes of hardness in the nugget, retreating side as well as advancing side for different compositions [8]. David et al reviewed the current techniques used for direct bonding of polymers, with a focus on thermoplastics [9]. Only few reports are there related to thermoplastics in FSW and Friction stir spot welding (FSSW) [10-13]. This paper addresses this absence by presenting a 
report on the effects of process parameters such as rotational speed, welding speed and tool pin profile for polypropylene plate achieved using FSW. Four different types of FSW pin profile were rotated at four different rotational speeds and four different welding speeds during the experiments. The effects of the process parameters on the weld region and hardness are measured and the microstructure of the weld zone is investigated.

\section{EXPERIMENTAL PROCEDURE}

FSW was performed on samples that were held using a specially designed clamping fixture that allowed the samples to be fixed on to a CNC vertical machining centre for welding. The samples used in this work consisted of two polypropylene plates with dimensions of $220 \times 100 \times 10 \mathrm{~mm}$ (length, width, depth) was prepared to fabricate FSW joints. The initial joint configuration was obtained by securing the plates in position using clamps. The direction of welding was normal to the rolling direction. Single pass welding procedure was used to fabricate the joints. The non-consumable rotating tools used in this study had four different FSW tool pin profiles such as Square pin, taper pin, Triangular pin, and Threaded pin with a cylindrical shank. The fixed pin type tool made in mild steel with a nominal pin diameter $6 \mathrm{~mm}$ and shoulder diameter of $24 \mathrm{~mm}$ and also pin length of $10 \mathrm{~mm}$ was used in the present investigation. Various nomenclature of tool is shown in Fig-2.

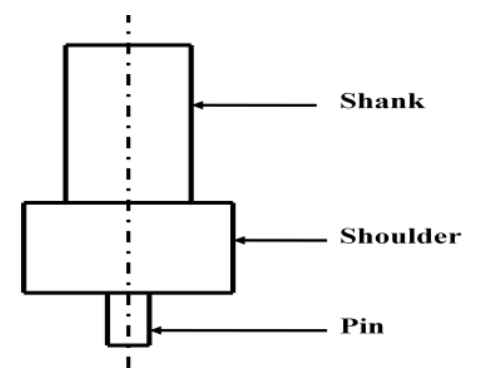

Fig-2: Various nomenclature of FSW tool

Design of experiments (DOE) is a powerful analysis tool for modeling and analyzing the influence of process variables over some specific variables, which is an unknown function of these process variables. The most important stage in the DOE lies in the selection of the control factors. As many as possible should be included, so that it would be possible to identify non-significant variables at the earliest opportunity. There are three different parameters used in this investigation such as tool pin profile, spindle speed, and welding speed. Taguchi defines the quality of a product, in terms of the loss imparted by the product to the society from the time the product shipped to the customer. Some of these losses are due to deviation of the product's functional characteristic from its desired value, and these are called losses due to functional variation. The uncontrollable factors which cause the functional characteristics of a product to deviate from their target values are called noise factors, which can be classified as external factors such as temperature and human factors, manufacturing imperfections due to variation of product parameter from unit to unit and product deterioration, etc. the overall aim of quality engineering is to make products that are robust with respect to all noise factors. Taguchi creates a standard orthogonal array to accommodate this requirement. Depending on the number of factors and their level, an orthogonal array is selected by the investigator is shown in Table 1 . In this experimental work, L'16 orthogonal array was utilized to identify the optimized parameters. Details of friction stir welding conditions are shown in Table 2. Sixteen different welding conditions were applied to these samples. Welding speeds were varied from 30 to $60 \mathrm{~mm} / \mathrm{min}$, and rotational speeds were varied from 1500 to $2250 \mathrm{rpm}$.

Table-1: Different process parameters and their levels

\begin{tabular}{|l|l|l|}
\hline S.No & parameter & levels \\
\hline 1 & $\begin{array}{l}\text { FSW tool pin } \\
\text { profile }\end{array}$ & $\begin{array}{l}\text { Square, Triangular, } \\
\text { Threaded, and Taper }\end{array}$ \\
\hline 2 & $\begin{array}{l}\text { Welding speed } \\
\text { mm/min }\end{array}$ & $30,40,50$, and 60 \\
\hline 3 & $\begin{array}{l}\text { Rotational speed } \\
\text { rpm }\end{array}$ & $\begin{array}{l}1500,1750,2000, \text { and } \\
2250\end{array}$ \\
\hline
\end{tabular}

Table-2: Experimental design based on the L'16 orthogonal array

\begin{tabular}{|l|l|l|l|}
\hline Run & Pin profile & $\begin{array}{l}\text { Feed rate in } \\
\mathrm{mm} / \mathrm{min}\end{array}$ & $\begin{array}{l}\text { Rotating } \\
\text { speed in } \\
\text { rpm }\end{array}$ \\
\hline 1 & Taper & 30 & 1750 \\
\hline 2 & Taper & 40 & 1500 \\
\hline 3 & Taper & 50 & 2250 \\
\hline 4 & Taper & 60 & 2000 \\
\hline 5 & Triangular & 30 & 2250 \\
\hline 6 & Triangular & 40 & 2000 \\
\hline 7 & Triangular & 50 & 1750 \\
\hline 8 & Triangular & 60 & 1500 \\
\hline 9 & Square & 30 & 1500 \\
\hline 10 & Square & 40 & 1750 \\
\hline 11 & Square & 50 & 2000 \\
\hline 12 & Square & 60 & 2250 \\
\hline 13 & Threaded & 30 & 2000 \\
\hline 14 & Threaded & 40 & 2250 \\
\hline 15 & Threaded & 50 & 1500 \\
\hline 16 & Threaded & 60 & 1750 \\
\hline
\end{tabular}

FSW joints were analyzed for microstructural studies. Microstructural characterization were taken across the cross section of friction stir welded region (parallel to the rolling direction). All samples were cut approximately $20 \mathrm{~mm}$ length. 
The samples were then manually ground and polishing in the polishing machine. The polished samples were etched in OXylene. Microstructural image were taken by the optical microscopy at a magnification of 100x, 200x and 400x. Rockwell hardness testing machine was used for hardness testing of FSW joints. The hardness values were measured at different distances (every $5 \mathrm{~mm}$ upto $15 \mathrm{~mm}$ ) from the centre of nugget with the load of $100 \mathrm{kgf}, 30$ second duration time and $1 / 4 "$ ball indenter.

\section{RESULT AND DISCUSSION}

\subsection{Friction Stir Welded region and their Micro}

\section{structural analysis}

FSW were successfully produced for different designed process parameters such as spindle speed of 1500-2250 rpm, welding speed of $30-60 \mathrm{~mm} / \mathrm{min}$, and four different FSW tool pin profiles (Taper, Triangular, Square and Threaded pin profile). The polypropylene plates were welded for sixteen different set of process parameters condition based on the L'16 orthogonal array in FSW process. In this experimental work, the friction stir welded joints for different designed set of parameters were analyzed and those welded region discussed in Fig-3a-18a. The nugget areas of the welded region were clearly visible and observed in those figures. Top of the joint interface and cross section of the welded region both were explained and for understanding of the welded region, focused particular region in those figures.

In fusion welding of metal alloys, the defects like porosity, hot cracks etc., decline the weld quality and joint properties. Usually, friction stir welded joints are free from these defects since there is no melting takes place during welding and the metals are joined in the solid state itself due to the heat generated by the friction and flow of metal by stirring action. However, FSW joints are prone to other defects like pin holes, tunnel defects, piping defects, kissing bond, cracks, etc... due to improper flow of metal and insufficient consolidation of metal in the FSW region[14]. But, when the welded region's cross section was evaluated in polypropylene materials, some cracks, pin holes, porosity, cavity and etc... appeared in the welded region.

The magnified cross sections as micro level of welded region were evaluated to analyze the defects and optimize the process parameters in the FSW process. So, the welded region's cross section was taken the micro structural images by using the optical microscopy for 100X, 200X, and 400X magnification that had discussed in the Fig- 3b-18b for the designed set of process parameters in FSW. Microstuctural images of nugget area for different set of process parameters were evaluated for identifying defects like cracks, blow holes, pin holes, cavity, porosity and etc.
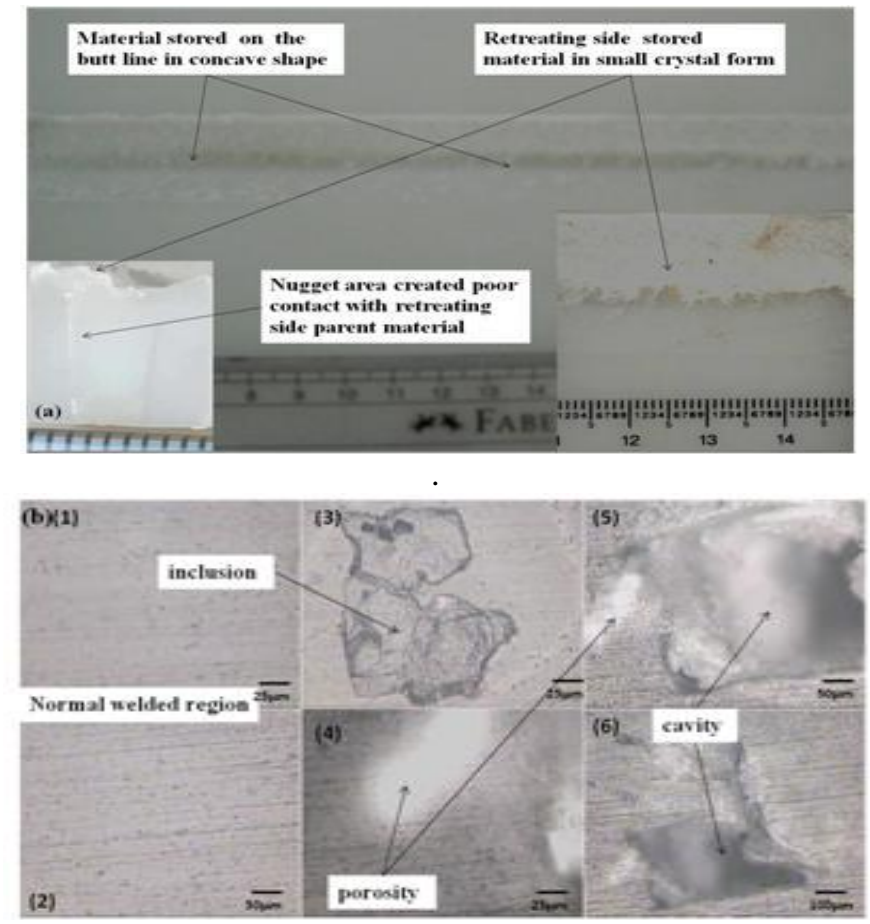

Fig-.3: a\&b. Appearance \& Microstructure of FSW region for Taper pin at rotational speed of $1750 \mathrm{rpm}$ and welding speed of $30 \mathrm{~mm} / \mathrm{min}$

FSW tool with Taper pin profile at rotational speed of 1750 $\mathrm{rpm}$ and welding speed of $30 \mathrm{~mm} / \mathrm{min}$ produced concave shape of the welded region and small crystal form of material appeared in the retreating side. The molded material consolidated in the nugget area very well even the poor contact with retreating side as shown the Fig-3a. The porosity, cavity and inclusion were appeared in the contact of retreating side's parent material as shown in the Fig-3b.

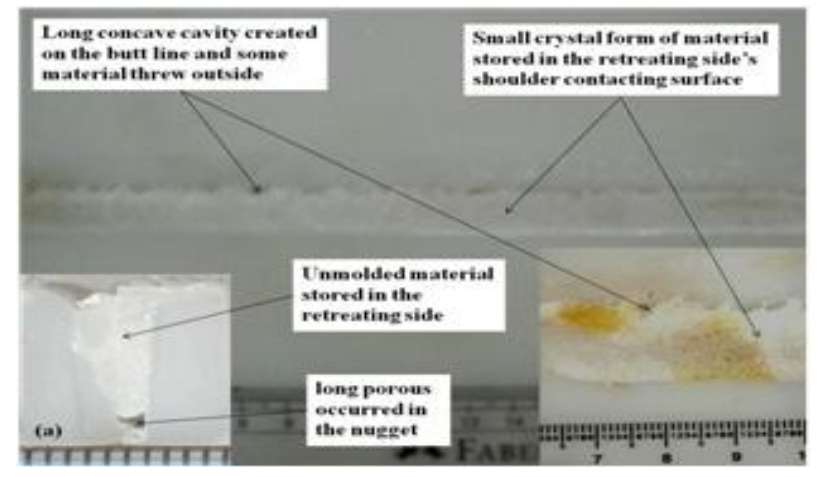




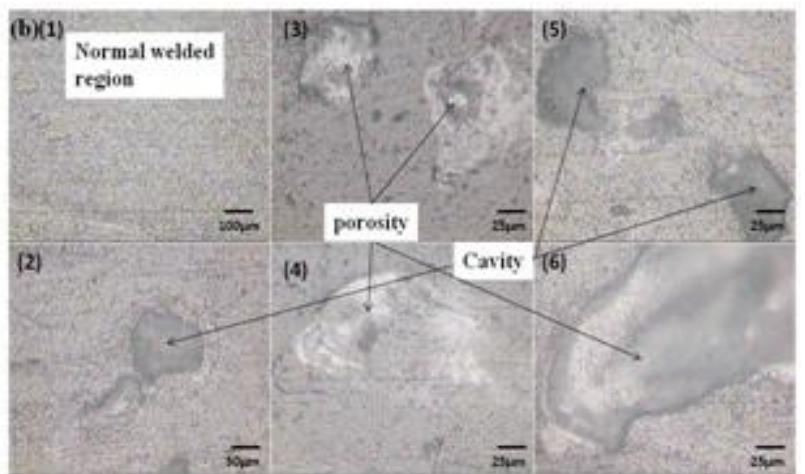

Fig-4: a\&b. Appearance \& Microstructure of FSW region for Taper pin at rotational speed of $1500 \mathrm{rpm}$ and welding speed of $40 \mathrm{~mm} / \mathrm{min}$

FSW tool with Taper pin profile at rotational speed of 1500 $\mathrm{rpm}$ and welding speed of $40 \mathrm{~mm} / \mathrm{min}$ produced long concave groove appeared in the joint interface and some amount of material threw outside. The material consolidation was not even in the entire length of joint interface. Even though the material appeared in the joint interface, it is not properly bonded in the advancing side, the unconsolidated material stored in the retreating side with poor contact of parent material. Small crystal form of material deposition was also appeared in this welding condition as shown the Fig- 4a. Due to the unmolded material in the retreating side, cavity and porosity appeared in macro as well as micro level images as shown the Fig- $4 b$.

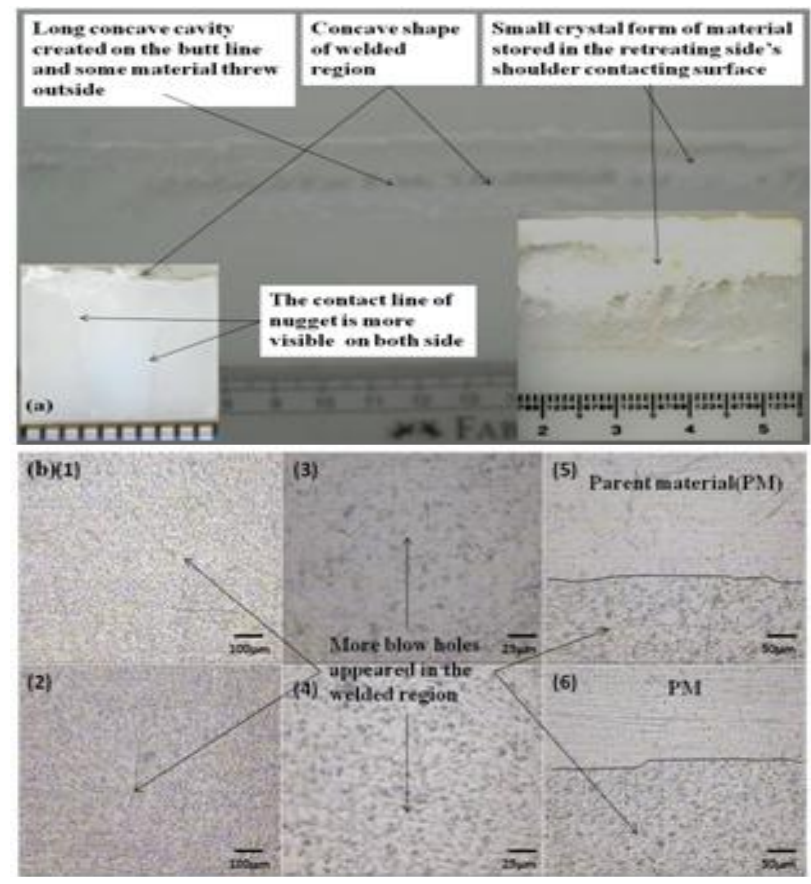

Fig-5: a\&b. Appearance \& Microstructure of FSW region for Taper pin at rotational speed of $2250 \mathrm{rpm}$ and welding speed of $50 \mathrm{~mm} / \mathrm{min}$
FSW tool with taper pin profile at rotational speed of 2250 $\mathrm{rpm}$ and welding speed of $50 \mathrm{~mm} / \mathrm{min}$ produced long cavity appearance in the joint interface. It developed concave shape of the welded region and small amount of the material accumulation. The material was normally consolidated in the entire length of the welded region with visible contact on AS\&RS as shown the Fig- 5a. So, when analyzed the micro images in Fig-5b, more number of blow holes appeared in the welded region.

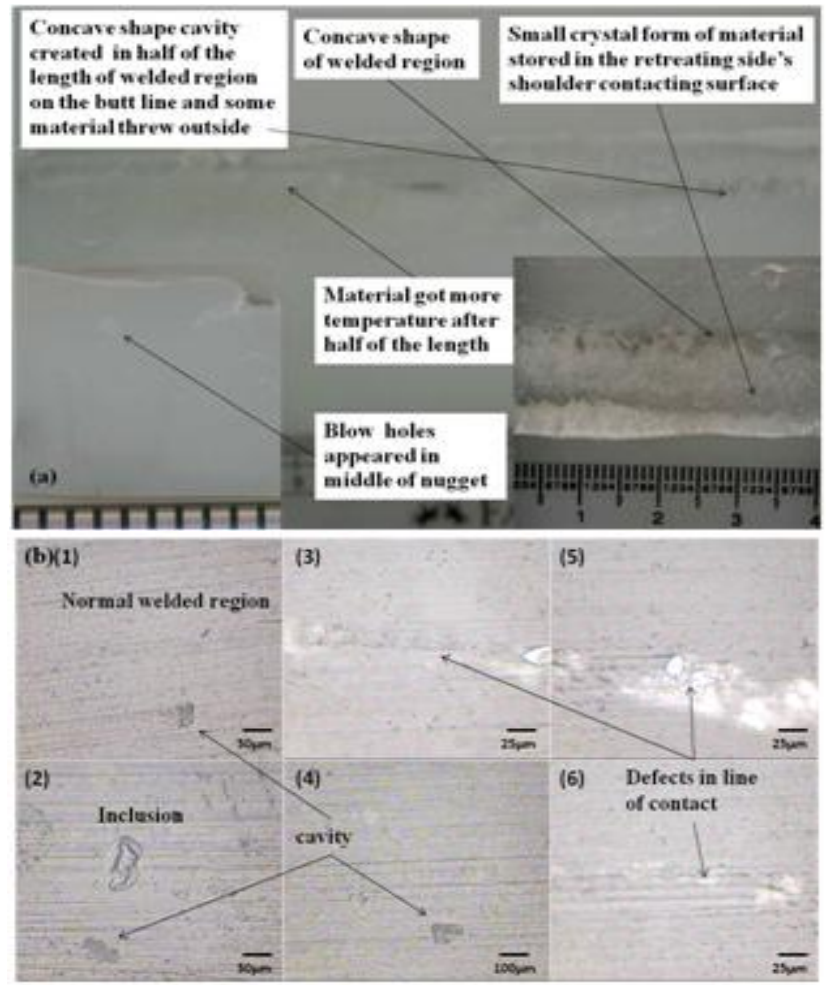

Fig-6: a\&b. Appearance \& Microstructure of FSW region for Taper pin at rotational speed of $2000 \mathrm{rpm}$ and welding speed of $60 \mathrm{~mm} / \mathrm{min}$

FSW tool with taper pin profile at rotational speed of 2000 $\mathrm{rpm}$ and welding speed of $60 \mathrm{~mm} / \mathrm{min}$ produced poor contact with the retreating side for half of the entire length and then somewhat better welded region formed due to the temperature changes in the remaining length as shown in the Fig-6a. Only few blow holes were appeared in the middle of the nugget. When the nugget area was analyzed by the microscopy, the minimum number of defects formed in this region such as cavity, inclusion and contact of parent material as explained in the Fig- 6b. 

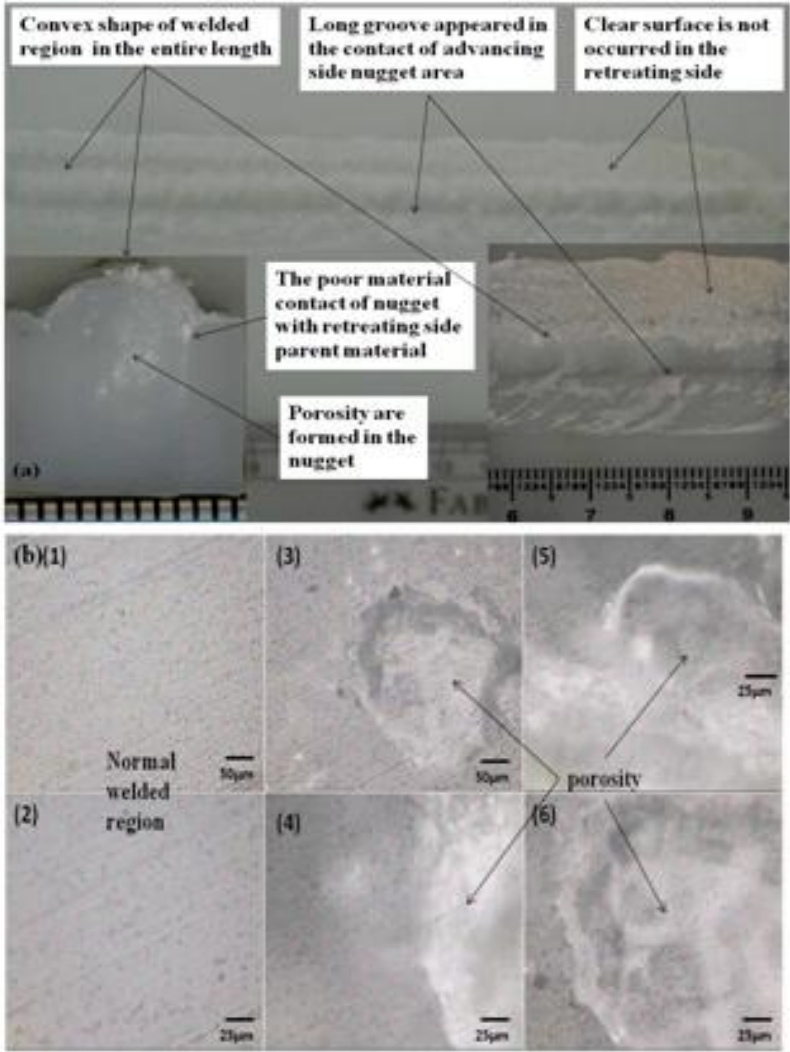

Fig-7: a\&b. Appearance \&Microstructure of FSW region for Triangular pin at rotational speed of $2250 \mathrm{rpm}$ and welding speed of $30 \mathrm{~mm} / \mathrm{min}$

FSW tool with triangular pin profile at rotational speed of $2250 \mathrm{rpm}$ and welding speed of $30 \mathrm{~mm} / \mathrm{min}$ produced convex shape of the welded region in the entire length of the joint interface. Due to the over heat in the advancing side, a small gap formed in the joint interface and developed rough surface in the retreating side when the tool shoulder rubbed the workpiece surface. The poor contact of nugget with retreating side's parent material and formed porosity in the cross section as shown in the Fig- 7a. More number of porosity was visible in microstructure as shown in the Fig- $7 \mathrm{~b}$.

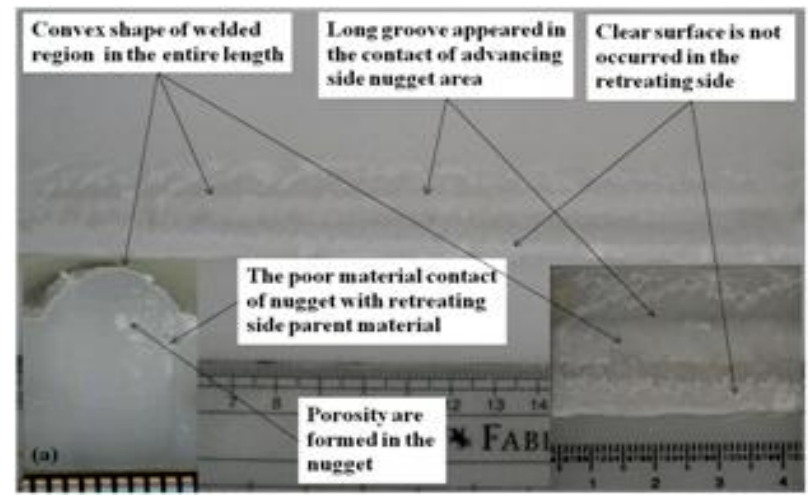

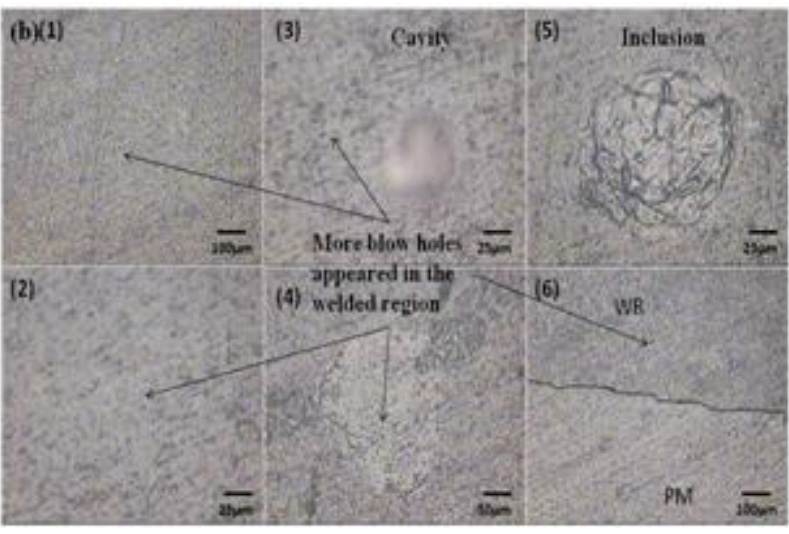

Fig-8: a\&b. Appearance \& Microstructure of FSW region for Triangular pin at rotational speed of $2000 \mathrm{rpm}$ and welding speed of $40 \mathrm{~mm} / \mathrm{min}$

The poor contact with the parent material and few porosity formation were continued in this condition also (FSW tool with triangular pin profile at rotational speed of $2000 \mathrm{rpm}$ and welding speed of $40 \mathrm{~mm} / \mathrm{min}$ ). One or two porous formed in nugget as shown the Fig- 8a. But, more blow holes appeared in the microstructure of welded region with one inclusion as shown in the Fig- 8 b.

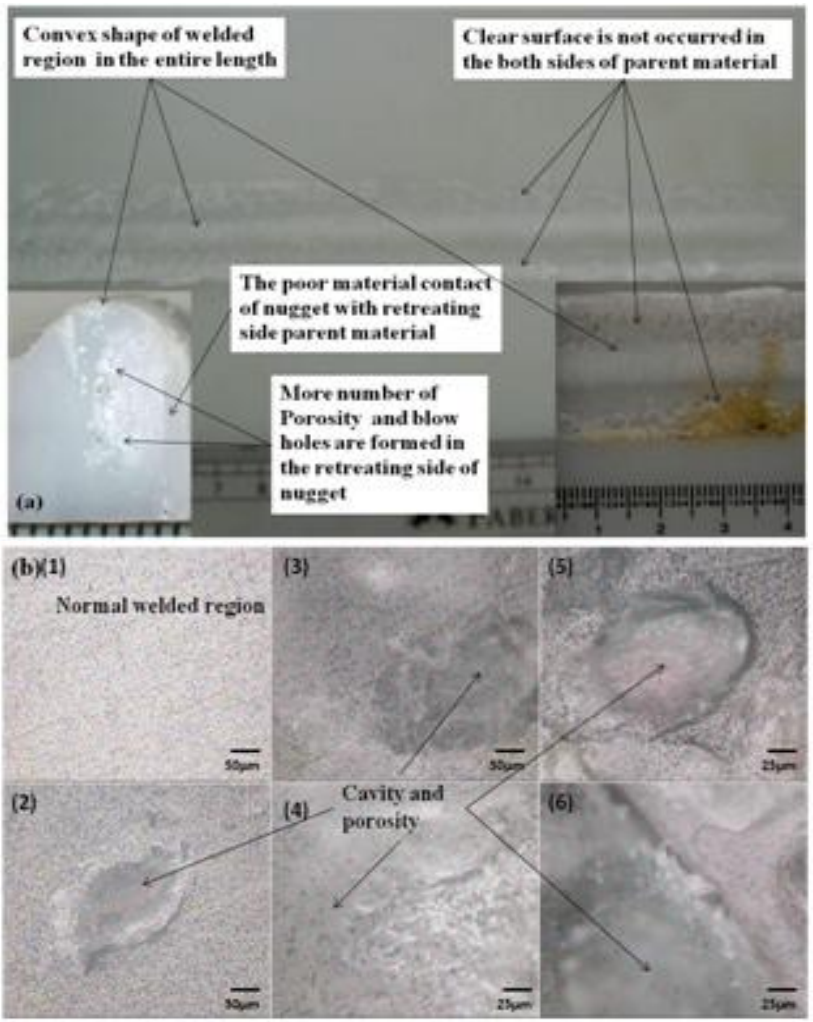

Fig-9: $a \& b$. Appearance \& Microstructure of FSW region for Triangular pin at rotational speed of $1750 \mathrm{rpm}$ and welding speed of $50 \mathrm{~mm} / \mathrm{min}$ 
In FSW tool with triangular pin profile at rotational speed of $1750 \mathrm{rpm}$ and welding speed of $50 \mathrm{~mm} / \mathrm{min}$, even though the convex shape of the welded region was formed in the top of the joint interface, defects were occurred in the form of porous, cavity and blow holes. This also created larger size cavity, porous and blow holes formed in the nugget area as shown in the Fig- 9. and also the poor material contact of nugget with retreating side as shown in the Fig- 9a. Some of the cavity and porous had more size in the images as shown in the Fig- 9b.

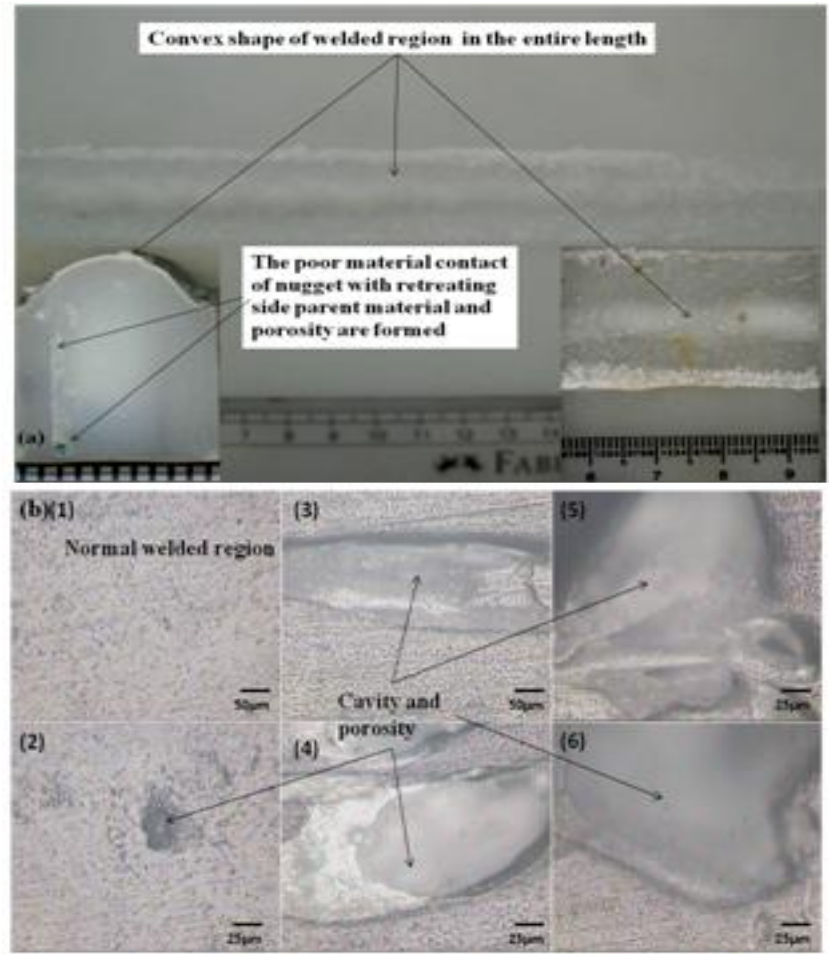

Fig-10: $a \& b$. Appearance \&Microstructure of FSW region for Triangular pin at rotational speed of $1500 \mathrm{rpm}$ and welding speed of $60 \mathrm{~mm} / \mathrm{min}$

In this experiment(FSW tool with triangular pin profile at rotational speed of $1500 \mathrm{rpm}$ and welding speed of 60 $\mathrm{mm} / \mathrm{min}$ ), number of defects reduced such as gap formation, material storage in both sides, and defects in nugget area. But, the poor material contact of nugget with retreating side and porosity appeared in this condition as shown in the Fig-10b.

FSW tool with square pin profile at rotational speed of 1500 $\mathrm{rpm}$ and welding speed of $30 \mathrm{~mm} / \mathrm{min}$ developed convex shape of the welded region in the entire length and small groove formed in the advancing side. Small crystal form of material stored in the retreating side. The porosity created in the middle of the nugget area as shown the Fig- 11a. Only the porosity and contact line defects enlarged in the microstructural images with inclusion. This was explained in the Fig-11b.

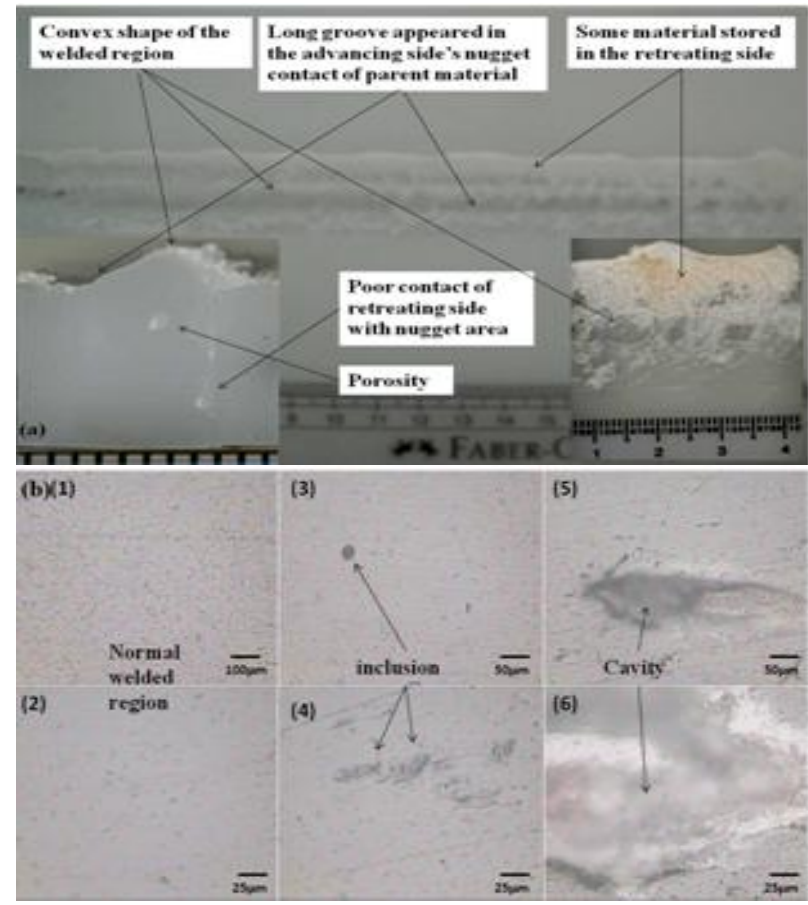

Fig-11: a\&b. Appearance \&Microstructure of FSW region for Square pin at rotational speed of $1500 \mathrm{rpm}$ and welding speed of $30 \mathrm{~mm} / \mathrm{min}$

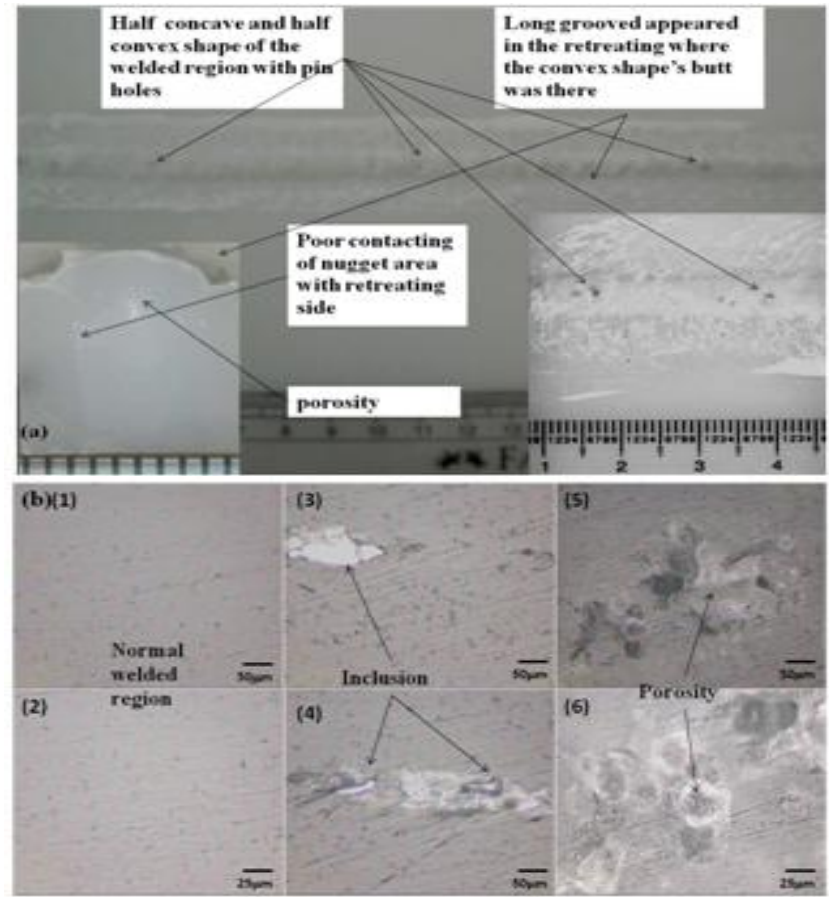

Fig-12: a\&b. Appearance \&Microstructure of FSW region for Square pin at rotational speed of $1750 \mathrm{rpm}$ and welding speed of $40 \mathrm{~mm} / \mathrm{min}$ 
The porosity, pin hole in the top surface of the welded region, and poor contact of parent material were developed as the defects in this parameter condition (FSW tool with square pin profile at rotational speed of $1750 \mathrm{rpm}$ and welding speed of $40 \mathrm{~mm} / \mathrm{min}$ ) as shown in the Fig- 12a. The few millimeter interior region of nugget had porosity this was clearly shown in the microstructure image as shown in the Fig- 12b.
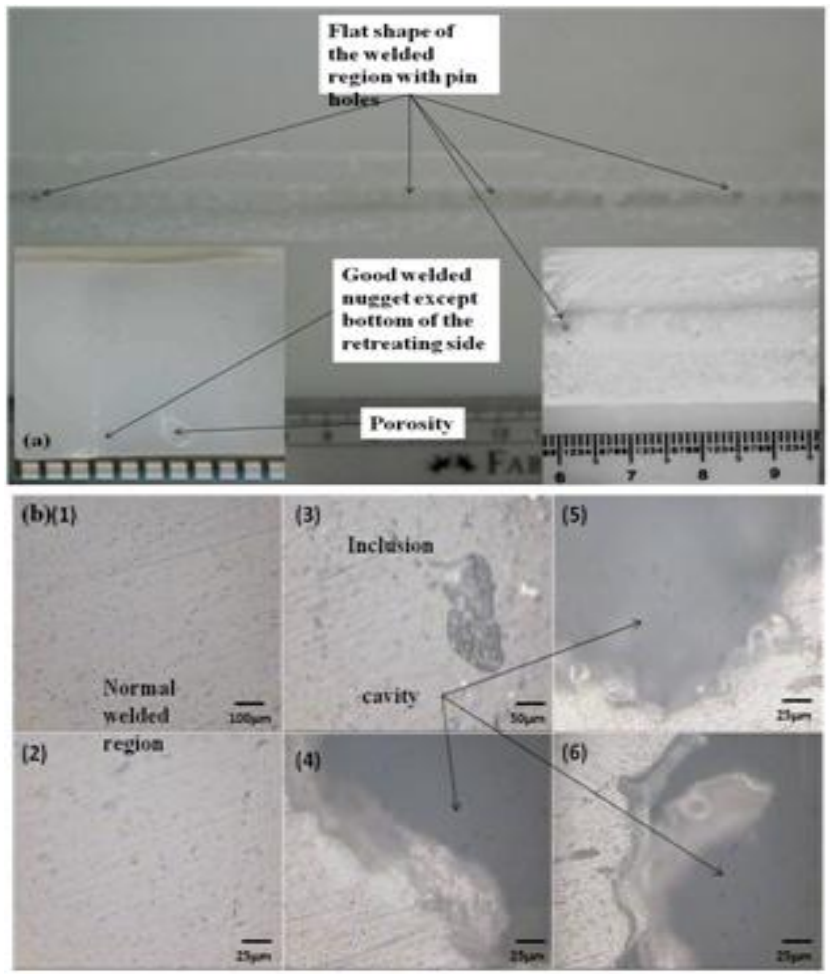

Fig-13: a\&b. Appearance \&Microstructure of FSW region for Square pin at rotational speed of $2000 \mathrm{rpm}$ and welding speed of $50 \mathrm{~mm} / \mathrm{min}$

Flat shape of the welded region occurred in this condition (FSW tool with square pin profile at rotational speed of 2000 $\mathrm{rpm}$ and welding speed of $50 \mathrm{~mm} / \mathrm{min}$ ) with some pin holes. If the welded nugget divided as two part as top portion and bottom portion, top portion did not have any defects and good contact with parent material. The bottom portion had porosity and poor contact with the parent material as shown in the Fig13a. A larger size porosity appeared in the welded region with some inclusion as shown in the Fig- 13b.

In FSW tool with square pin profile at rotational speed of 2250 $\mathrm{rpm}$ and welding speed of $60 \mathrm{~mm} / \mathrm{min}$, pin holes did not develop in the joint interface and also good contact of nugget with parent material. But, few porosity and cavity appeared in the weld nugget as shown in the Fig- 14a\&b. The material deposition was even in the AS\&RS.

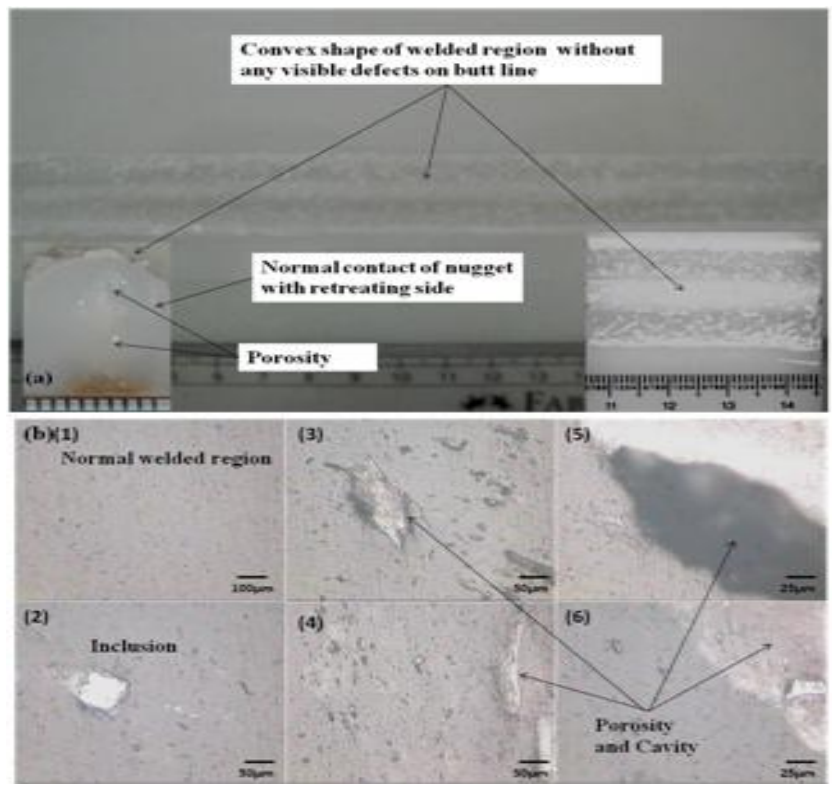

Fig-14: a\&b. Appearance \&Microstructure of FSW region for Square pin at rotational speed of $2250 \mathrm{rpm}$ and welding speed of $60 \mathrm{~mm} / \mathrm{min}$

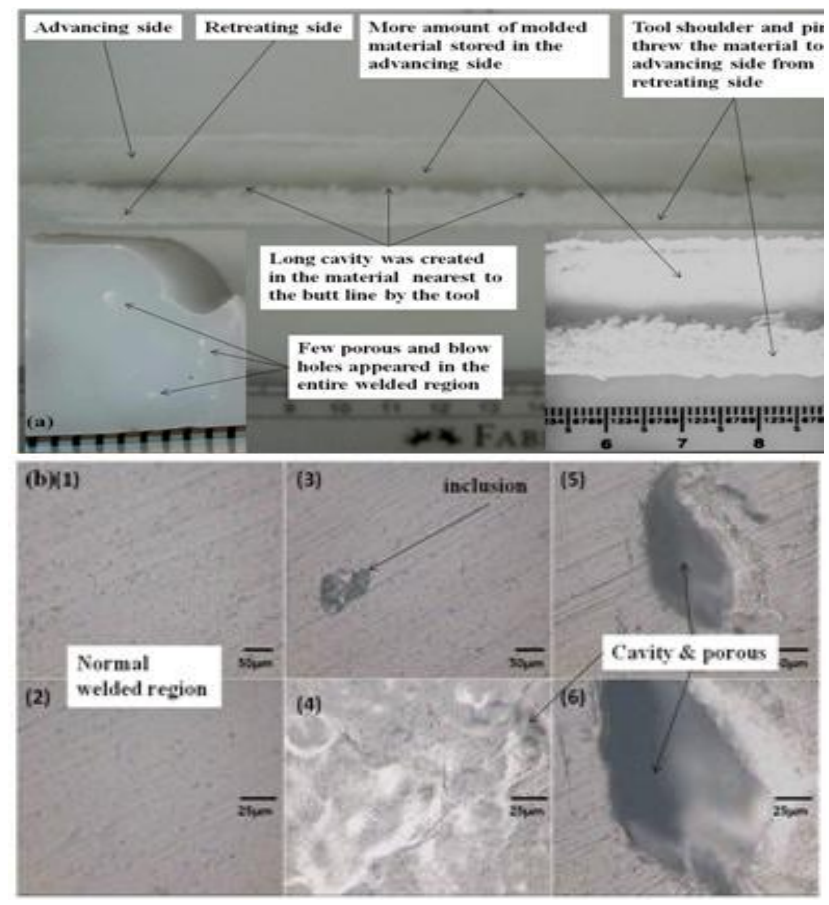

Fig-15: a\&b. Appearance \&Microstructure of FSW region for Threaded pin at rotational speed of $2000 \mathrm{rpm}$ and welding speed of $30 \mathrm{~mm} / \mathrm{min}$

Due to the over heat in this condition (FSW tool with threaded pin profile at rotational speed of $2000 \mathrm{rpm}$ and welding speed of $30 \mathrm{~mm} / \mathrm{min}$ condition), tool shoulder picked the colloidal material from the retreating side and developed long cavity in 
the retreating side and also more amount of material consolidated in the advancing side. Few porous and blow holes appeared in the entire welded region (see Fig- 15a\&b). Contacting line of parent material in the retreating side had half of the plate thickness after the tool passed in the joint interface.
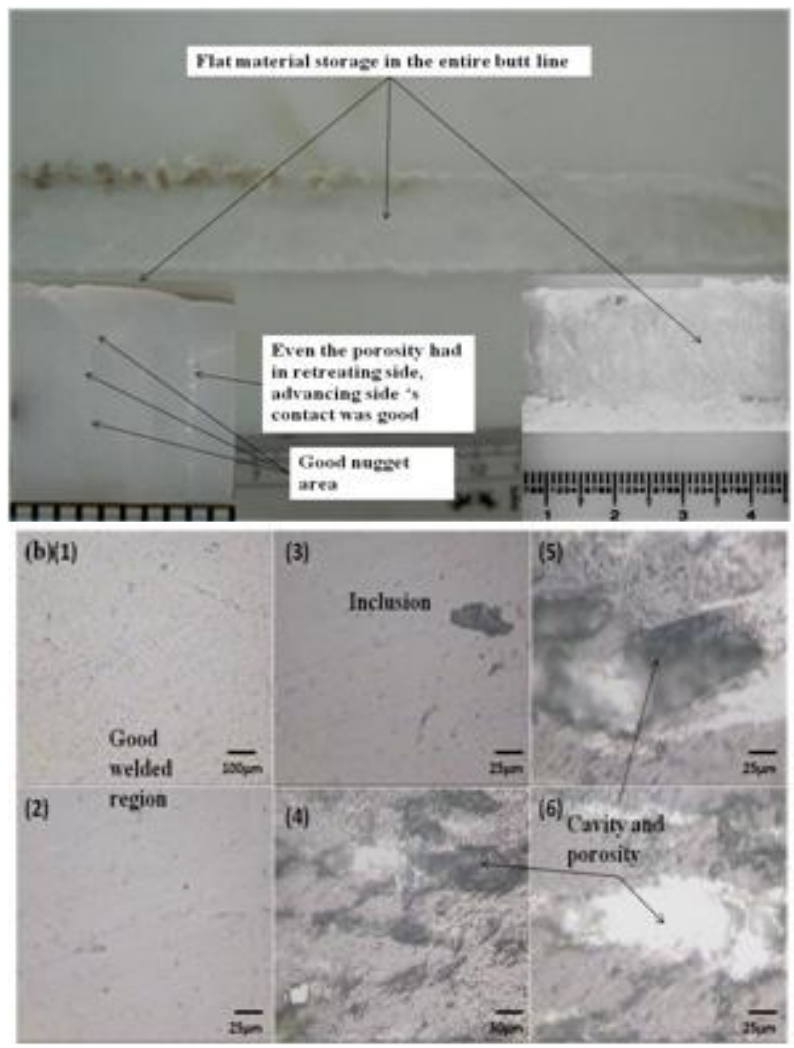

Fig-16: a\&b. Appearance \&Microstructure of FSW region for Threaded pin at rotational speed of $2250 \mathrm{rpm}$ and welding speed of $40 \mathrm{~mm} / \mathrm{min}$

In FSW tool with threaded pin profile at rotational speed of $2250 \mathrm{rpm} \&$ welding speed of $40 \mathrm{~mm} / \mathrm{min}, 1500 \mathrm{rpm} \& 50$ $\mathrm{mm} / \mathrm{min}$, and $1750 \mathrm{rpm} \& 60 \mathrm{~mm} / \mathrm{min}$, material consolidated as flat form in the entire length. Good welded region developed in these conditions. Even the advancing side's contact was better, the normal contact line of nugget with retreating side occurred with one or two porosity in the macro and micro structural images as shown in the Fig- 16-18. Good nugget area developed in these welded regions without any porosity, blow holes and other defects.

For the spindle speed except $1500 \mathrm{rpm}$, the welded region could not be analyzed as correct way based on the spindle speed because each spindle speed gave different welded qualities for different tool pin and feed rate of the designed set of process parameters in FSW process. Apart from the contact of nugget area with retreating side's parent material, the effects of welded region analyzed and tabulated in Table 3.
When the welded region were analyzed, the contact line of nugget with retreating side was the major problem in the all those conditions. If that defect will reduce, the strength of the welded region mostly improve in all experimental condition.

Table-3: Effects of welded region based on the spindle speeds

\begin{tabular}{|l|l|l|l|l|}
\hline $\begin{array}{l}\text { Spindle } \\
\text { speed/ Pin } \\
\text { profile }\end{array}$ & $1500 \mathrm{rpm}$ & $\begin{array}{l}1750 \\
\mathrm{rpm}\end{array}$ & $\begin{array}{l}2000 \\
\mathrm{rpm}\end{array}$ & $\begin{array}{l}2250 \\
\mathrm{rpm}\end{array}$ \\
\hline Taper & Normal & Poor & Poor & Ok \\
\hline Triangular & Normal & Ok & Poor & Good \\
\hline Square & Normal & Poor & Poor & Good \\
\hline Threaded & Normal & Good & Good & Good \\
\hline
\end{tabular}

\subsection{Analysis of Rockwell hardness in the welded}

\section{region}

Rockwell hardness of the welded polypropylene plate for all set of process parameters were evaluated in the nugget area and 15 millimeter with 5 millimeter interval on the both side parent material from the middle of joint interface. Those values are tabulated in the Table 4 and presented in Chart-1. The left side data mentioned the advancing side hardness and the right side data mentioned the retreating side hardness in the Chart-1.

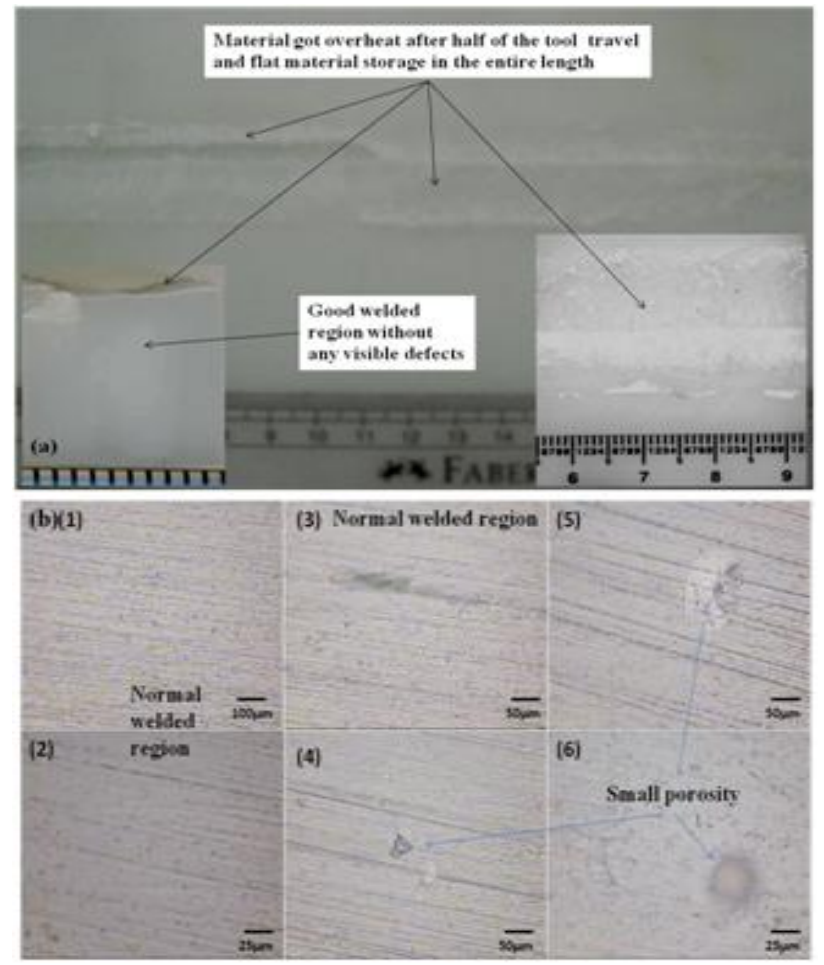

Fig-17: a\&b. Appearance \&Microstructure of FSW region for Threaded pin at rotational speed of $1500 \mathrm{rpm}$ and welding speed of $50 \mathrm{~mm} / \mathrm{min}$ 


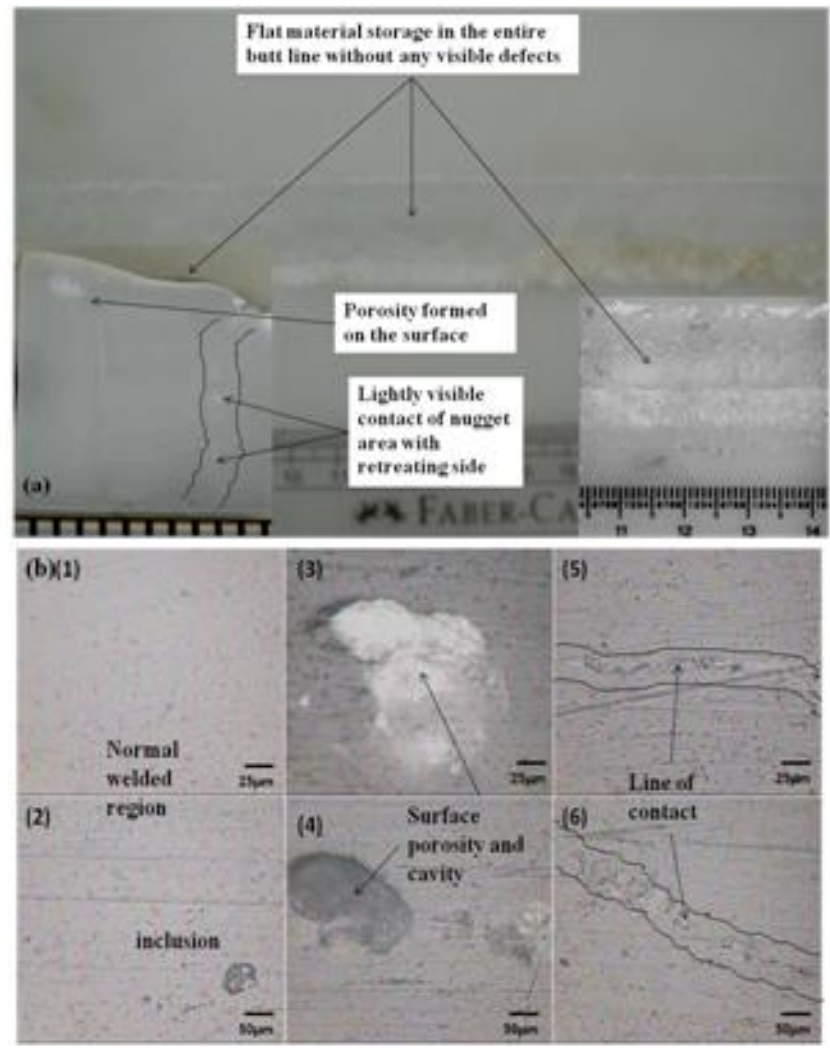

Fig-18: a\&b. Appearance \&Microstructure of FSW region for Threaded pin at rotational speed of $1750 \mathrm{rpm}$ and welding speed of $60 \mathrm{~mm} / \mathrm{min}$

Table-4: The Rockwell hardness distribution middle, advancing side as well as retreating side for each $5 \mathrm{~mm}$ upto $15 \mathrm{~mm}$

\begin{tabular}{|l|l|l|l|l|l|l|l|}
\hline $\begin{array}{l}\text { S. } \\
\text { No }\end{array}$ & \multicolumn{3}{|l|}{$\begin{array}{l}\text { Advancing } \\
\text { in mm }\end{array}$} & side & Middle & \multicolumn{2}{l}{$\begin{array}{l}\text { Retreating } \\
\text { in mm }\end{array}$} \\
\cline { 2 - 5 } \cline { 7 - 9 } & 15 & 10 & 5 & & 5 & 10 & 15 \\
\hline 1 & 76 & 71 & 70 & 55 & 68 & 71 & 76 \\
\hline 2 & 76 & 71 & 70 & 55 & 70 & 72 & 76 \\
\hline 3 & 76 & 71 & 70 & 57 & 70 & 72 & 76 \\
\hline 4 & 76 & 71 & 69 & 60 & 69 & 71 & 76 \\
\hline 5 & 73 & 70 & 68 & 65 & 66 & 69 & 72 \\
\hline 6 & 72 & 70 & 68 & 66 & 67 & 70 & 72 \\
\hline 7 & 72 & 70 & 69 & 66 & 67 & 69 & 71 \\
\hline 8 & 72 & 71 & 70 & 67 & 67 & 69 & 71 \\
\hline 9 & 72 & 70 & 68 & 67 & 70 & 71 & 72 \\
\hline 10 & 72 & 70 & 68 & 68 & 70 & 71 & 72 \\
\hline 11 & 72 & 70 & 68 & 68 & 69 & 70 & 71 \\
\hline 12 & 72 & 70 & 69 & 69 & 69 & 70 & 72 \\
\hline 13 & 73 & 71 & 70 & 69 & 69 & 70 & 72 \\
\hline 14 & 73 & 72 & 71 & 70 & 70 & 71 & 72 \\
\hline 15 & 73 & 72 & 71 & 70 & 70 & 70 & 72 \\
\hline 16 & 73 & 72 & 71 & 69 & 70 & 71 & 73 \\
\hline
\end{tabular}

Process heat is not the only factor for a successful FSW process. Other factors, such as welding speed, rotational speed of the tool and tool pin profiles are all important factors for a successful FSW process. These factors influence the temperature distribution in the workpiece, and eventually, the control of the temperature becomes the key factor that affects the final properties of the weld [14]. The temperature changes were occurred due to the different process parameters that were focused in this hardness investigation. Normally, the temperature profiles on the retreating side are slightly lower than those on the advancing side. Those similar conditions occurred in hardness profiles of polypropylene material in FSW process.

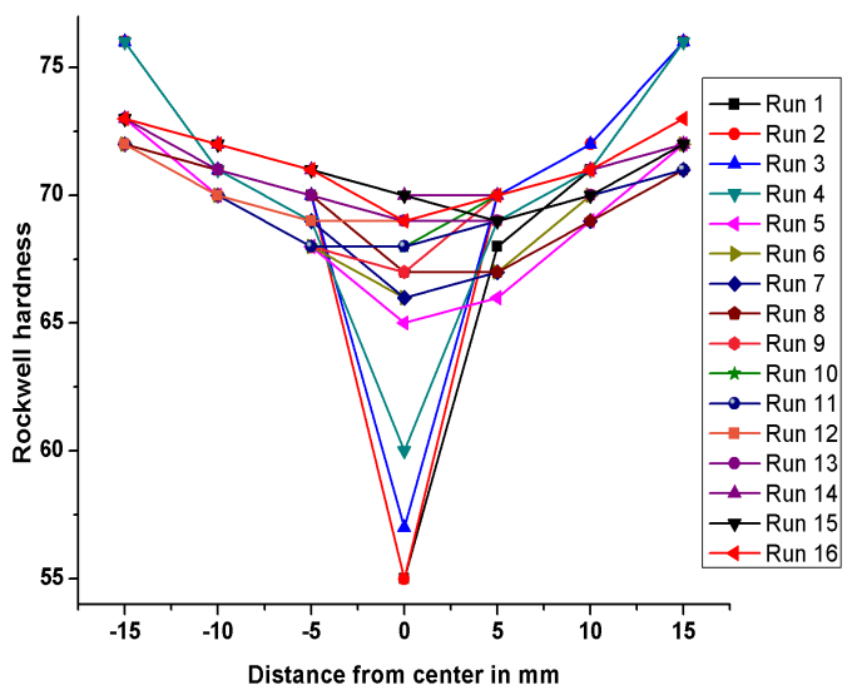

Chart-1: Effects of different process parameters on hardness

The hardness of base material has a range of 74-76 RH. However, the hardness near welded region shows variables value from 55-70 $\mathrm{RH}$. The hardness on the retreating side was slightly lower than those on advancing side. But, there is no much difference in hardness between the both sides as shown the Chart 1. The left side of the chart mentioned advancing side and right side mentioned retreating side. The most of the nugget area's hardness had only $65-70 \mathrm{RH}$ except three nugget area. Taper pin created very poor welded region with low hardness. Depend upon the heat affection on the both sides, the hardness changes occurred upto particular length. Taper pin did not create more hardness in the middle. So, the temperature rises was also very low in the middle and both sides. But, for other pin profiles, hardness increased upto 70 $\mathrm{RH}$ in the middle and heat affected on the both sides (see the Table 4 and Chart 1). The threaded tool pin created more hardness for all conditions without bothering of welding speed and spindle speeds as well as the threaded pin produced good welded region without more defects in the joint interface and nugget area. 


\section{CONCLUSIONS}

The study has demonstrated that polypropylene plate material can be joined using FSW process. The effects of the processing parameters were investigated by microstructure and Rockwell hardness. From this investigation, threaded tool pin profile created good welded region and more hardness without bothering of welding speed and rotational speed. The poor contact line of nugget area with advancing side's parent material is followed for all designed process parameters with various effects. Even the square pin produced good nugget area, some pin holes appeared in the joint interface. That may be affected the strength of the joints. Triangular pin developed good outer look as convex profile for all experimental conditions. But, those had more interior defects such as porous, poor contact, blow hole, and etc. The taper pin did not create good welded region for all the conditions. In the microstructure and hardness testing based investigation, the welding speed and rotational speed both the parameters were depended only the tool pin profile. There is no much difference occurred based on the welding speed and rotational speed.

\section{REFERENCES:}

[1]. Bahemmat P, Haghpanahi MK, Rahbari A, Salekrostam R. Mechanical micro and macrostructural analysis of AA7075-T6 fabricated by friction stir butt welding with different rotational speeds and tool pin profiles. ImechE-part B2009;224:419-433.

[2]. Abbasi Gharacheh M, Kokabi AH, Daneshi GH, Shalchi B Sarrafi R. The influence of the ratio of rotational speed transverse speed on mechanical properties of AZ31 friction stir welds. Int $\mathbf{J}$ Mech Tools-2006; 46:1983-1987.

[3]. Mishra RS, Mab ZY. Friction stir welding and processing. Mater.sci.engg part R-2005;50:1-78.

[4]. Rowe CED, Wayne Thomas. Advances in tooling materials for friction stir welding.Technical report. International publication by TWI 13th January-2005.

[5]. Won-Bae Lee, Seung-Boo Jung, The joint properties of copper by friction stir welding. Journal of materials letters 58 (2004) 1041-1046.

[6]. Hwang Y.M., Fan P.L., Lin C.H., Experimental study on friction stir welding of copper metals. Journal of materials processing technology 210 (2010) 16671672.

[7]. Chowdhury S.M, Chen D.L, Bhole S.D, Cao X. Tensile properties of a friction stir welding magnesium alloy: Effect of pin tool thread orientation and weld pitch. Journal of Materials science and engineering A527 (2010) $6064-6075$.

[8]. Sauvage .X, Dede. A, Cabello MunoZ. A, Huneau. B, Precipitate stability and recrystallisation in the weld nuggets of friction stir welded $\mathrm{Al}-\mathrm{Mg}-\mathrm{Si}$ and $\mathrm{Al}-\mathrm{Mg}$ -
Sc alloys. Journal of materials science and engineering A 491 (2008) 364-371.

[9]. Negin Amanat, Natalie L. james, David R. McKenzie, Welding methods for joining thermoplastic polymers for the hermatic enclosure of medical devices. Journal of Medical Engineering and physics 32 (2010) 690-699.

[10]. Mustafa Kemal Bilici, Ahmet Irfan Yukler, Influence of tool geometry and process parameters on microstructure and static strength in friction stir spot welded polyethylene sheets. Journal of Materials and Design 33 (2012) 145-152.

[11]. Mustafa Kemal Bilici, Application of Taguchi approach to optimize friction stir spot welding parameters of polypropylene. Journal of Materials and Design 35 (2012) 113-119.

[12]. Mustafa Kemal Bilici, Ahmet Irfan Yukler, Memduh Kurtulmus, The optimization of welding parameters for friction stir spot welding of high density polyethylene sheets. Journal of Materials and Design 32 (2011) 4074-4079.

[13]. Zoltan Kiss, Tiber Czigany, Applicability of Friction stir welding in Plolmeric materials. Journal of Mechanical Engineering 51/1 (2007) 15-18.

[14]. Elangovan K., Balasubramanian V. Influence of pin profile and rotational speed of the tool on the formation of friction stir processing zone in AA2219 aluminum alloy. Materials science engineering A 459 (2007) 7-18.

\section{BIOGRAPHIES:}

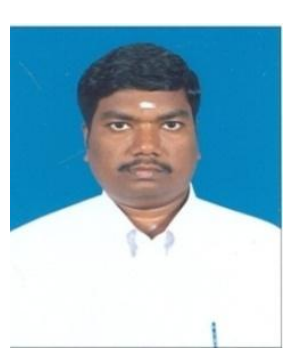

K. Panneerselvam is currently working as Assistant Professor in Department of production Engineering, NITT, Tamilnadu, India. He did his Ph.D. (Welding) from NITT, Tamilnadu, India. He has published nine research papers in national and international journals and twenty one papers in conferences. His research interests are Advance composite material processing, modeling and optimization of process parameters.

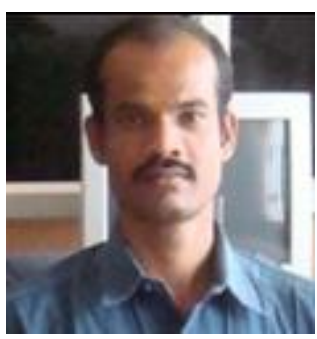

K. Lenin is Research scholar in Department of production Engineering, NITT, Tamilnadu, India. $\mathrm{He}$ is doing Ph.D. from NITT, Tamilnadu, India. His research interests are Advance composite material processing. 